\title{
Assessment of the General Knowledge of Emergency Physicians from Hospitals of the City of Salvador (Brazil) on the Care of Cardiac Arrest Patients
}

\author{
Nivaldo Menezes Filgueiras Filho, Antônio Carlos Bandeira, Thales Delmondes, Adriano Oliveira, Alberto Soares Lima \\ Junior, Vinicius Cruz, Fábio Vilas-Boas, Álvaro Rabelo Junior \\ Universidade Federal da Bahia, Faculdade de Medicina, Hospital Universitário Professor Edgard Santos, Salvador, BA, Brazil
}

Objective: To identify the proportion of emergency physicians certified in immersion courses (ACLS - Advanced Cardiac Life Support and ATLS - Advanced Trauma Life Support) correlating the variables of age, gender, medical specialty, academic title, and type of hospital with the level of theoretical knowledge on the care of Cardiac Arrest (CA) victims.

Methods: Emergency physicians from public and private hospitals of the city of Salvador, State of Bahia - Brazil, were consecutively evaluated from November, 2003 to July, 2004. They volunteered to participate in the study, and responded to a questionnaire consisting of information on the following variables of interest: professional profile, participation or not in ACLS and ATLS immersion courses, and cognitive assessment with 22 objective questions on Cardiopulmonary Resuscitation (CPR).

A score of correct answers was calculated for each participant, and then designated as score variable. This questionnaire was validated based on the result of the score obtained by ACLS course instructors in Salvador, BA.

Results: Of the 305 physicians who responded to the questionnaire, $83(27.2 \%)$ had attended the ACLS course and had a mean score variable of $14.9+3.0$ compared with the 215 physicians $(70.5 \%)$ who had not attended the course and whose mean was $10.5+3.5(p=0.0001)$. The mean score of the 65 cardiologists $(21.5 \%)$ was $14.1+3.3$ compared with the mean of $9.7+3.7(p=0.0001)$ of the 238 physicians $(78.5 \%)$ from other specialties. No difference was observed in the mean scores between physicians who had attended the ATLS course or not $(p=0.67)$.

Conclusion: In the sample studied, theoretical knowledge on CPR was higher among physicians who had attended the ACLS course, as opposed to those who had attended the ATLS course. Cardiologists who had attended the ACLS demonstrated a higher theoretical knowledge on the care of CA patients when compared to physicians from other specialties taken as whole - Internal Medicine, Surgery, and Orthopedics.

Key words: Cardiopulmonary resuscitation, ACLS (Advanced Cardiac Life Support), medical training.

Measures adopted in the cardiac arrest (CA) setting should be of proven efficacy and started within the shortest possible time interval. Thus, when managing a CA, time is the major determinant of success, since each minute lost reduces the survival rate by $10 \%{ }^{1}$. To achieve this purpose, it is fundamental to establish procedural guidelines and management. Emergency physicians should be able to promptly recognize, diagnose and perform maneuvers, thus providing the adequate treatment. In situations of imminent life threat, decisionmaking should be prompt. Therefore, knowledge and training in resuscitation are of the utmost importance for professionals working in emergency services. The use of flowcharts seems to help in the decision-making process. Flowcharts have been disseminated and used for teaching in training courses such as the ACLS - Advanced Cardiac Life Support.

The ATLS course resulted from the effort of the American College of Surgeons in systematizing the care of trauma patients based on current scientific evidences. Mortality and morbidity associated with trauma are a complex and serious problem in the western society, since they significantly affect part of the economically active population and place a significant burden on the health system in terms of rehabilitation and treatment. The introduction of ATLS to systematize trauma care led to a significant reduction in mortality, mainly after the first hour and in patients with very severe lesions ${ }^{2}$.

ACLS (The Advanced Cardiac Life Support and Advanced Trauma Life Support are international courses recognized worldwide by the acronyms ACLS and ATLS, respectively) was developed by the AHA (American Heart Association) in the 1970 's. Since then, ACLS training programs have multiplied. In 1995, more than 300,000 people were trained in the United States. In Brazil, as of 1997, approximately 3900 physicians, nurses, and physical therapists have been trained by the National Committee on Resuscitation (NCR) of the Fund on 
Improvement and Research in Cardiology (FunCor) of the Brazilian Society of Cardiology (BSC) ${ }^{3}$.

ACLS provides Basic Life Support (BLS) and Advanced Cardiac Life Support training in hospital facilities for health professionals. Some studies are favorable to $^{4,5,6,7}$ while others question ${ }^{8,9,10}$ the results of these courses as regards the effect of physician and nurse training on the efficacy of Cardiopulmonary Resuscitation (CPR) and survival rates. Another important factor in this context is the physicians' proficiency in Cardiopulmonary Resuscitation measures. The majority of specialists accept that courses like the ACLS make physicians more efficient in the treatment of CA patients. Thus, in the United States, the majority of hospitals have BLS and ACLS-trained physicians and nurses, and this training is mandatory for professionals who provide emergency care.

These issues have been seldom addressed in the Brazilian literature, and we found only one study conducted in a capital of a Southeastern Brazilian State assessing the impact of the presence, in the resuscitation team, of an ACLS-trained physician or nurse on the survival rate of CA patients ${ }^{7}$.

Thus, further local studies are necessary to assess the theoretical knowledge of emergency physicians working in private and public hospitals, and also to correlate these results with their having attended or not Advanced Cardiac Life Support (ACLS) and Advanced Trauma Life Support (ATLS) courses.

\section{Methods}

This is a cross-sectional study using a convenience sampling that included 305 emergency physicians (general practitioners, cardiologists, surgeons, and orthopedists) who worked in adult emergency rooms of 18 public and private hospitals in the city of Salvador (State of Bahia, Brazil). After explanation of the purposes of the study and reading of the Written Consent Form, the eligible physicians agreed to respond to a specific questionnaire from which information on the variables of interest would be collected. This questionnaire included: a) the physician's profile: age, gender, medical specialty, academic titles, attendance or not to ACLS or ATLS courses, and time when the courses were concluded or revalidated; b) cognitive assessment with 22 objective questions on CPR.

Each questionnaire applied was identified with a number corresponding to one emergency physician. The questionnaire was applied to each physician by Psychology and Medicine students. All information contained in the questionnaire was previously submitted to ACLS course instructors from the training center in Salvador, Bahia, in a pilot study. This result was used to validate the questionnaire. Data collection was performed from November, 1st, 2003 to July, 1st, 2004.

Statistical analysis - Data from the 305 participants of the total sample were analyzed as regards the following variables: age, gender, marital status, medical specialty, academic title, medical college attended, and hospital where the emergency physician worked. Simple frequencies and proportions, and cumulative frequencies and proportions were calculated.

A score of correct answers to the cognitive questions (cog 1 to $\operatorname{cog} 22$ ) was calculated for each participant. This value represented the sum of the number of correct answers; the result was defined by a score and indicated as the score variable. The calculation of the proportion of correct answers, defined as the number of correct answers divided by 22 (number corresponding to the total of questions) was also calculated.

For the distribution of values of the score variable, a BoxPlot with the minimum value, maximum value and distribution quartiles was drawn.

For the total sample, the mean and distribution quartiles of the stratified score variable were also estimated for the following variables: hospital where the physician worked, gender, ACLS course, ATLS course, medical specialty, type of hospital (public or private).

The differences of values of the score variable between the subgroups were calculated using the Wilcoxon-Mann-Whitney test. The subgroups analyzed were: ACLS course, ATLS course, medical specialty, and type of hospital (public or private).

The Microsoft Office Word 2003, Microsoft Office Excel 2003, SAS for Windows version 6.11, and StatXact-3 version 3.0.1 software programs were used to perform and analyze the database. Values of $p$ lower than or equal to $5 \%(p \leq 0.05)$ were considered statistically significant.

\section{Results}

From November, 2003 to July, 2004, 305 questionnaires were filled out by emergency physicians in 18 hospital of the city of Salvador, Bahia. Of these, five were public and 13 were private hospitals.

Physicians were divided into four different categories according to their medical specialty: internal medicine, surgery, orthopedics and cardiology, as shown in Table 1. Two physicians did not give information on their specialty. Of the 303 (100\%) who answered this question, 118 (38.9\%) were general practitioners, $111(36.3 \%)$ were surgeons, 65 $(21.5 \%)$ were cardiologists and $9(3.0 \%)$ were orthopedists. Of the total sample, 202 (66.2\%) were males and 103 (33.8\%) were females.

\begin{tabular}{|lll|}
\hline $\begin{array}{l}\text { Medical } \\
\text { Specialty }\end{array}$ & Frequency $\mathbf{n}$ & Percentage (\%) \\
$\begin{array}{l}\text { General } \\
\text { Practitioner }\end{array}$ & 118 & 38.9 \\
\hline Surgeon & 111 & 36.3 \\
\hline Cardiologist & 65 & 21.5 \\
\hline Orthopedist & 9 & 3.0 \\
\hline Total & 303 & 100 \\
\hline Gender & Frequency $\mathbf{n}$ & Percentage (\%) \\
\hline Male & 202 & 66.2 \\
\hline Female & 103 & 33.8 \\
\hline Total & 305 & 100 \\
\hline Table 1 - Distribution of emergency physicians according to their \\
\end{tabular}




\section{Original Article}

Regarding the frequency of emergency physicians who had attended training courses, we verified that $83(27.2 \%)$ had attended the ACLS, whereas 215 (70.5\%) had not, and $7(2.3 \%)$ did not provide information. In relation to the ATLS, 99 (32.5\%) had attended the course and 204 (66.9\%) had not. Two emergency physicians ( $0.6 \%$ ) did not provide information. These data are shown in Tables 2 and 3.

\begin{tabular}{|lll|}
\hline ACLS & Frequency $\mathbf{n}$ & Percentage (\%) \\
\hline Yes & 83 & 27.2 \\
No & 215 & 70.5 \\
Did not answer & 7 & 2.3 \\
\hline Total & 305 & 100 \\
\hline Table 2 - Distribution of emergency physicians according to \\
attendance or not of ACLS course
\end{tabular}

\begin{tabular}{|lll|}
\hline ATLS & Frequency $\mathbf{n}$ & Percentage (\%) \\
\hline Yes & 99 & 32.5 \\
No & 204 & 66.9 \\
Did not answer & 2 & 0.6 \\
\hline Total & 305 & 100 \\
\hline Table 3 & Distribution of emergency physicians according to \\
& attendance or not of ATLS course \\
\hline
\end{tabular}

When the emergency physician was asked whether he had had any training in Cardiopulmonary Resuscitation (CPR) during his medical course, the answer was positive in 224 questionnaires $(73.4 \%)$, and negative in $77(25.2 \%)$. Four (1.4\%) did not answer.

In Figure 1, the Box-Plot shows the distribution of values of the score variable in relation to the total population of the study. The minimum value was 2 , the maximum value was 20 , the median was 12 , the 25 th quartile was 9 , and the 75 th quartile was 15.

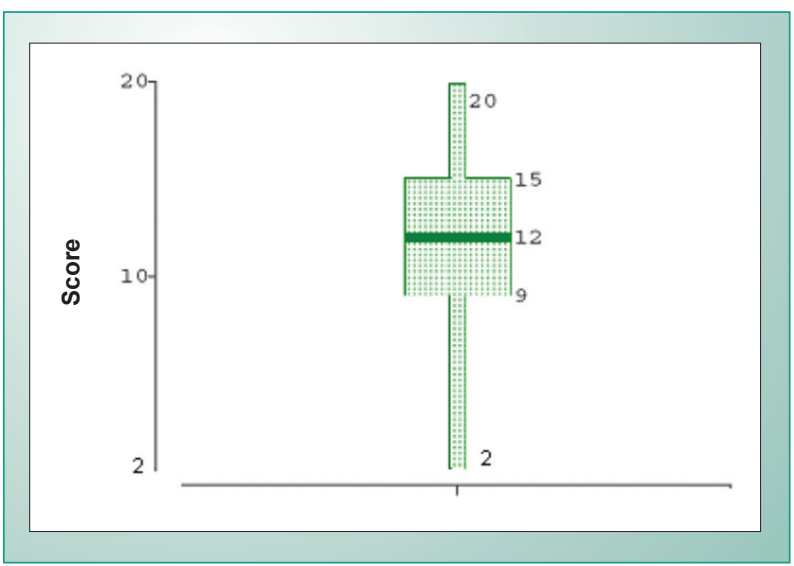

Fig. 1 - Distribution of the values of the score variable, with minimum value, maximum value, and quartiles in relation to the total study population. The score ranged from 2 to 20 , the median was 12, and the mean proportion of correct answers was $54.5 \%$.
The mean score according to gender was $11.4 \pm 4.0$ for males and $12.3 \pm 3.6$ for females $(p<0.05)$. The mean score of physicians who had attended the ATLS course or not was $11.6 \pm 3.5$ and $11.8 \pm 4.0$, respectively $(p=0.665)$. Regarding medical specialties, the mean scores were 14.1 \pm 3.3 for cardiologists; $11.8 \pm 3.9$ for general practitioners; $10.6 \pm 3.4$ for surgeons; and $6.8 \pm 2.2$ for orthopedists. The mean of private and public hospitals was $11.9 \pm 3.9$ and $11.3 \pm 3.9$ $(p=0.237)$, respectively.

The mean score of ACLS instructors was 19.8, ranging from 18 to 21 .

Analysis of differences of values in the score variable among different subgroups:

\section{- $\quad$ ACLS}

The mean score of the 83 emergency physicians (27.2\%) who had attended the ACLS was 14.9+3.0, whereas that of the 215 physicians (70.5\%) who had not attended was $10.5+3.5$. This difference was statistically significant $(p=0.0001)$ - Figure 2. The stratified analysis of the 231 physicians from other specialties (excluding cardiologists), divided into two groups - those who had attended $(n=47)$ or not $(n=184)$ the ACLS course, showed a statistically significant difference $(p=0.0001)$.

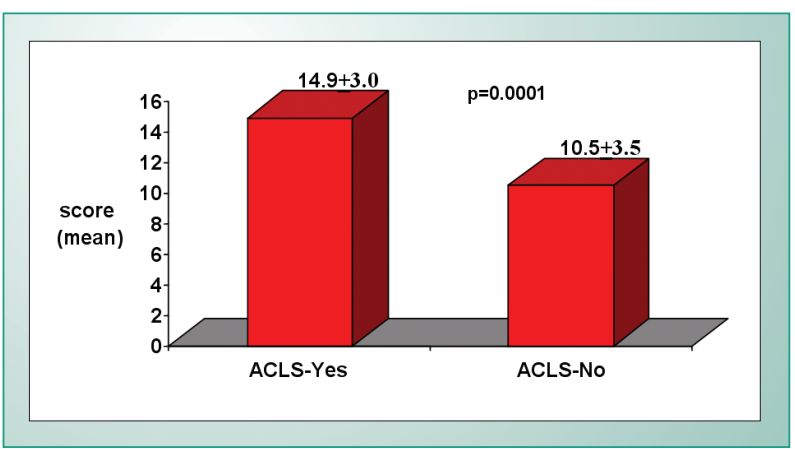

Fig. 2 - Comparison between the mean scores of the cognitive assessment of emergency physicians who had attended or not the ACLS training.

Cardiologists $(n=65)$ were divided into two groups, with and without ACLS. The group of cardiologists who had attended the ACLS course had a score of 15.4 \pm 2.9 , whereas those who had not attended the course had a score of $12.4 \pm 3.2$; this difference was statistically significant in favor of those who had attended the course $(p=0.001)$, thus demonstrating the impact of the course on these specialists, as shown in Figure 3.

The stratified analysis of the 83 physicians who had attended the ACLS course, divided into two groups - cardiologists $(n=36)$ and non-cardiologists $(n=47)$, did not show any statistically significant difference $(p=0.269)$, thus suggesting the impact of the course, regardless of specialty, as shown in Figure 4.

The score obtained by the general practitioners and surgeons who had not attended the ACLS course was 10.3 \pm 3.4 , and by the cardiologists who also had not attended the course was $12.4 \pm 3.2$. This difference was statistically significant $(p=0.002)$, demonstrating a difference of proficiency related to the specialty among emergency physicians who had not 


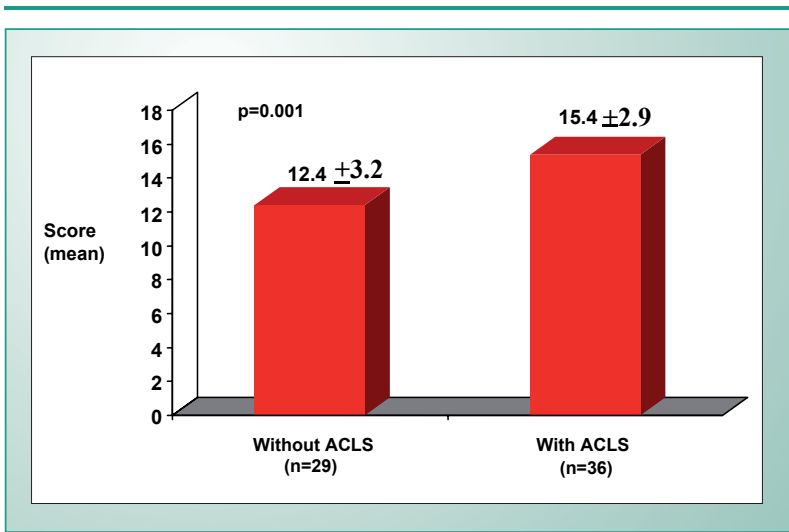

Fig. 3 - Comparison between the mean scores of the cognitive assessment of cardiologists who had attended or not the Advanced Cardiac Life Support (ACLS).

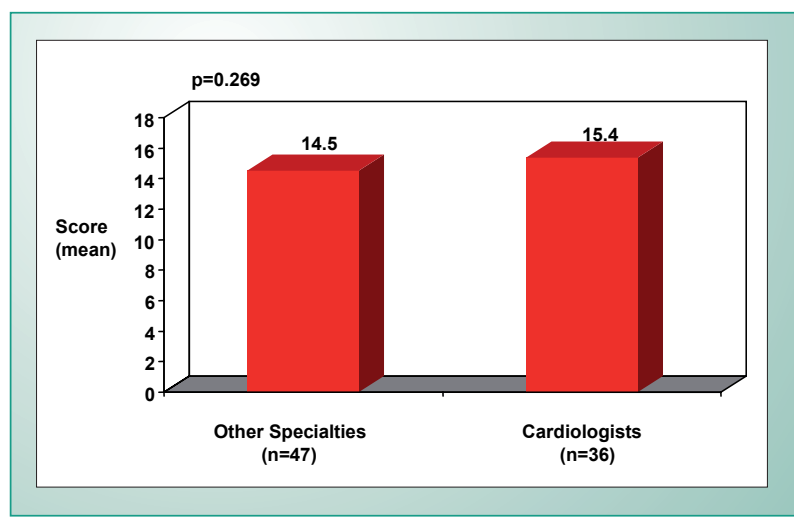

Fig. 4 - Comparison between the mean scores of the cognitive assessment of cardiologists and non-cardiologists who had attended the Advanced Cardiac Life Support (ACLS).

attended the course. This is shown in Figure 5.

Among not-ACLS-trained cardiologists, the score observed was $12.4 \pm 3.2(n=29)$, whereas among ACLS-trained physicians from other specialties (non-cardiologists), the score was $14.6 \pm 3.1(n=47)$; this difference was statistically significant $(p=0.003)$. Data are shown in Figure 6 . This result corroborates the impact of ACLS on medical proficiency in resuscitation, regardless of specialty.

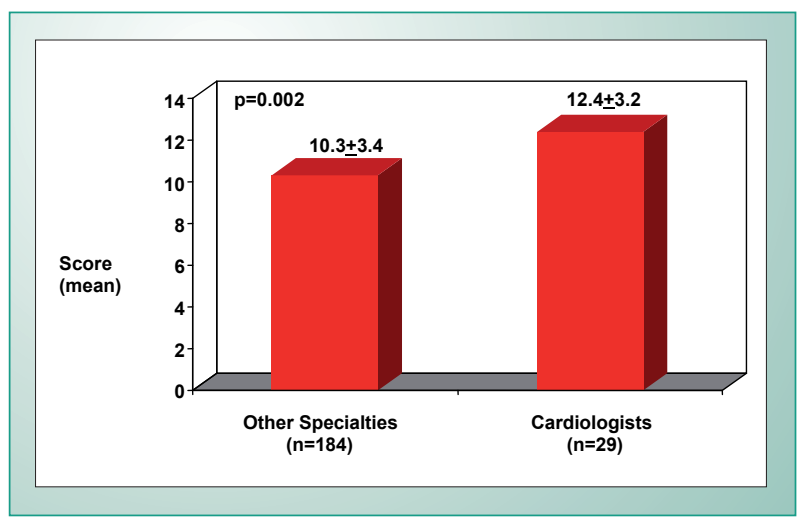

Fig. 5 - Comparison between the mean scores of the cognitive assessment of cardiologists and non-cardiologists who had not attended the Advanced Cardiac Life Support (ACLS).

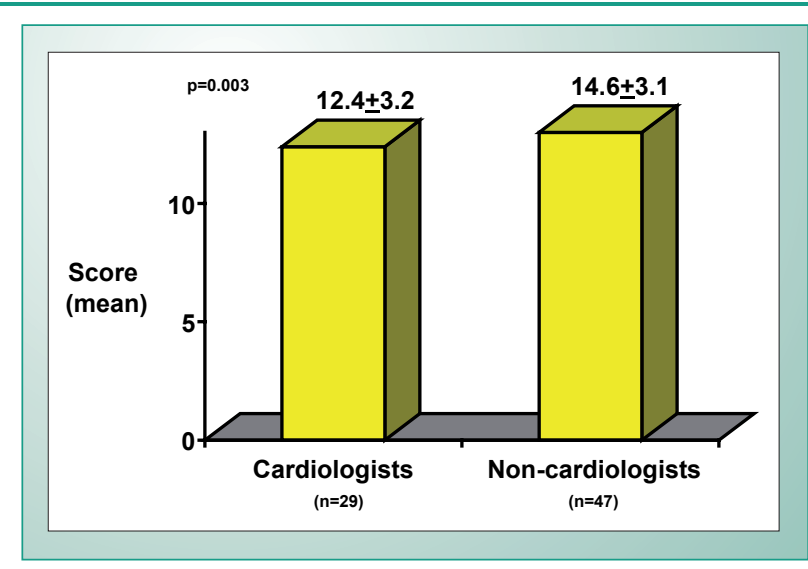

Fig. 6 - Comparison between the mean scores of the cognitive assessment of cardiologists who had not attended the ACLS and physicians from other specialties who had attended the training.

\section{- $\quad$ ATLS}

The mean score of the 99 emergency physicians (32.5\%) who had attended the ATLS was 11.6 \pm 3.5 ; whereas that of the 204 physicians (66.9\%) who had not attended the course was 11.8 \pm 4.0 . This difference was not statistically significant, as shown in Figure $7(p=0.665)$.

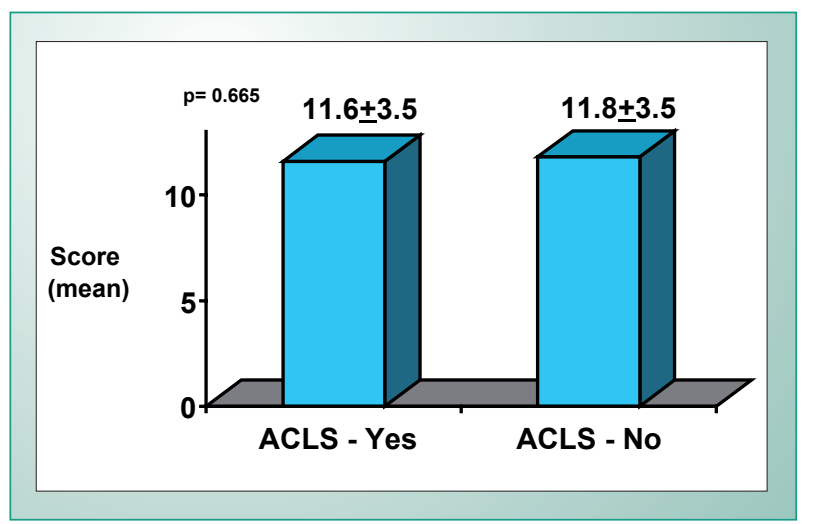

Fig. 7 - Comparison between the mean scores of the cognitive assessment of emergency physicians who had attended or not the ATLS training.

\section{- $\quad$ Specialty - Cardiology}

The mean score variable of the 65 cardiologists (21.5\%) was $14.1 \pm 3.3$, whereas that of the 238 physicians $(78.5 \%)$ from other specialties was $9.7 \pm 3.7$. This difference was statistically significant ( $p=0.0001$ ) (Figure 8). This difference resulted from the fact that a greater number of cardiologists had attended the ACLS, since the proportion of these cardiologists was 2.72 greater than that of general practitioners and surgeons who had attended the course.

- $\quad$ Public versus Private Hospital

The mean score variable of the 97 emergency physicians (31.8\%) from public hospitals who responded to the questionnaire was $11.3 \pm 3.9$, whereas that of the 208 physicians $(68.2 \%)$ from private hospitals was $11.9 \pm 3.9$. No statistically significant difference was observed $(p=0.237)$, as shown in Figure 9. 


\section{Original Article}

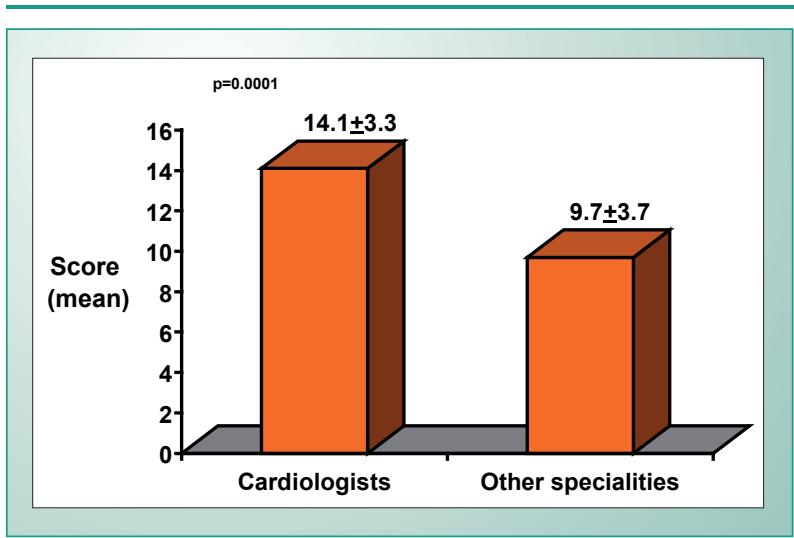

Fig. 8 - Comparison between the mean scores of the cognitive assessment of cardiologists and those of other specialists.

\section{Discussion}

This study sought to evaluate the profile and level of theoretical knowledge on CPR of physicians who work in emergency services of public and private hospitals of the city of Salvador - State of Bahia, Brazil, comparing those who had attended ACLS and ATLS training courses with those who did not. A deficiency in knowledge on resuscitation was identified in the 305 physicians of the sample, characterized by a mean of correct answers of 12 out of a total of 22 questions, with a mean proportion of correct answers of $54.5 \%$. Data from the literature are consistent with our findings. Thus, Galinski M et $\mathrm{al}^{11}$ observed insufficient theoretical knowledge on Basic Life Support (BLS) in the cases of physicians and nurses who responded to a questionnaire in a 450-bed French university hospital. Of a total of 996 questionnaires, 571 (57\%) were filled out -158 by physicians and 413 by nurses. Noteworthy in this study, in the group of physicians managing a CA, is the fact that $50 \%$ opened the airway, $75 \%$ started ventilation, $86 \%$ started external cardiac compression, only $42 \%$ asked for help,thus denoting an inadequate management . Failure to ask for help is a serious mistake during CPR training, since this causes a delay in the availability of a defibrillator - the only equipment able to revert a CA. Diaz et al ${ }^{12}$ applied a questionnaire to 63 family physicians in the city of Quemado de Guines, Villa Clara, in Cuba, demonstrating that they had an acceptable theoretical knowledge despite insufficient resuscitation training. However, in that study, physicians showed deficiencies in managing the airway. Another study ${ }^{13}$ conducted in public hospitals in the city of Quito, Ecuador, demonstrated that $62.3 \%$ of the 151 physicians surveyed did not know how to use a defibrillator, and only $39.4 \%$ believed themselves fully proficient in CPR. Although $68.6 \%$ had been trained in resuscitation, $2.4 \%$ gave wrong answers to all the 10 questions on Advanced Cardiac Life Support - ACLS. Wheatley et $\mathrm{al}^{14}$ also used a questionnaire to assess physicians and nurses from Monterrey, Nuevo Leon, Mexico, as regards their level of knowledge on resuscitation. Based on the training reported by the professionals, three groups were formed: A) with informal training; B) without any training; and C) with formal training. Group $\mathrm{C}$ had $77 \%$ of correct answers when compared with the $64 \%$ obtained by the other groups $(p<0.001)$. In the group that had informal access to training, only $30 \%$ had practiced

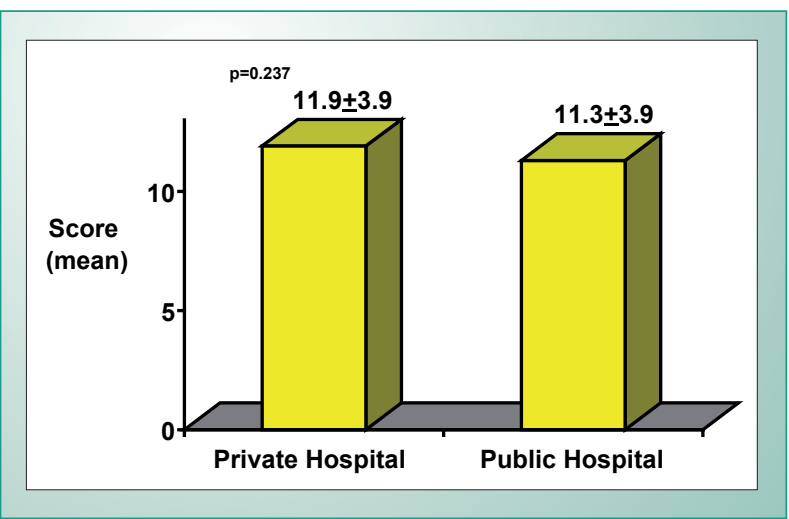

Fig. 9 - Comparison between the mean scores of the cognitive assessment of emergency physicians who responded to the questionnaire in public or private hospitals.

on a CPR manikin. Birnbaum et al ${ }^{15}$ applied a test to physicians and nurses of 12 rural hospitals in Wisconsin, United States, and found inadequate knowledge on ACLS. In that study, only $39.6 \%$ of the nurses and $64.1 \%$ of the physicians correctly identified a third degree atrioventricular block, whereas 33\% of the nurses and $22 \%$ of the physicians could not identify an overt ventricular fibrillation. The evidences of these studies are consistent with those observed in our study.

In the present study, the mean score of physicians who had attended or not the ACLS course was $14.9 \pm 3.0$ and $10.5 \pm 3.5$, respectively, thus demonstrating a statistically significant difference in theoretical knowledge. This occurred despite the fact that the great majority $(73.5 \%$ of the emergency physicians) had been trained in CPR during their medical course, thus demonstrating a failure in the educational system as regards resuscitation. In the literature, we found studies that assessed the effect of training on the performance of CPR and on survival rates. Lowenstein et $\mathrm{al}^{8}$ verified inadequate management of lethal arrhythmias by physicians on duty, and no difference was observed when these professionals had previously ACLS training. Mancini and Kaye ${ }^{9}$ assessed the performance of ACLS-trained resident physicians during the occurrence of intra-hospital resuscitations, and showed inadequate performance of CPR, insufficient team leadership, difficulties in operating equipment and failure to follow the algorithm sequence. However, when Shanon et al ${ }^{4}$ tested the ability of surgeons to manage the airway, use monitor and defibrillator, and recognize and treat tachycardia, ventricular fibrillation, asystole and complete heart block, they verified that arrhythmia and defibrillation were recognized with a significantly higher efficiency among those who had previously attended the ACLS.

A Canadian controlled multicenter intervention study ${ }^{10}$ evaluated in two phases - before and after Advanced Cardiac Life Support (ACLS) training of paramedics - the effect on survival to discharge. This study showed that the systematic introduction of ACLS training in the pre-hospital care had not decreased mortality, when a rapid defibrillation program had been previously implanted. However, Dane et $\mathrm{al}^{8}$ evaluated the result of CA patient care provided by ACLS-trained or nontrained nurses in a tertiary 550-bed hospital in Georgia, United States. The survival rate was four-fold higher when the nurse 
assisting the patient was ACLS trained, and this variable was considered an independent predictor in the logistic regression analysis. In an observational multicenter prospective study conducted in São Paulo, Brazil, Moretti also demonstrated that the presence of at least one ACLS-trained person in the team assisting the CA increased by up to two times the chance of success of immediate event reversion.

In our study, when we analyzed the emergency physicians who had attended or not the ATLS course, we did not identify any difference in the knowledge on CPR. The mean score was $11.6 \pm 3.5$ and $11.8 \pm 4.0$, respectively. The ATLS course is focused on emergency care of trauma patients, and it does not include any specific training on the treatment of CA patients; this is probably why no difference was found. It should be noted that almost no cardiologist had attended this course, thus no statistical analysis could be carried out.

Another interesting finding in this study was the clear difference in the theoretical knowledge of emergency physicians who had attended the ACLS, regardless of their specialty. When a stratified analysis of all non-cardiologists was made, dividing them into two groups (those who had attended or not this course), a statistical difference was identified. When cardiologists were likewise divided into two groups, with and without ACLS, a higher score was observed among those who had attended the course, thus showing the impact of the course even among specialists. When all physicians who had attended the ACLS, divided into two groups - cardiologists and other specialties - were analyzed, no difference was observed between the groups, thus demonstrating the importance of the course in the improvement of knowledge, regardless of specialty. We also analyzed the scores of cardiologists who had not attended the ACLS, and compared them to those of physicians from other specialties who had attended the course, and found higher scores among those who had attended the ACLS, despite their not being cardiologists. Consistent with our data, Canesin and Grion ${ }^{16}$ assessed 92 physicians, all holding a specialist's title, and demonstrated a higher level of knowledge on CPR among those who had attended the ACLS course versus those who did not.

The fact that no difference was found between the scores of physicians from public or private hospitals could be explained by the good performance of physicians from the University Hospital Professor Edgard Santos, which accounted for the increased mean score regarding public hospitals. In this case, the reason is clear, since the only emergency service of the hospital is comprised exclusively of cardiologists. Consistent with our study, Devlin $\mathrm{M}^{17}$ assessed nurses from a Southeastern hospital in England as regards their Basic Life Support (BLS) skills, and compared them with those of nurses from public hospitals. Deficiencies were found in both groups, regardless of the type of hospital.

In our study, no difference in the level of theoretical knowledge was found between clinicians and surgeons. The mean score was $11.8+3.9$ for clinicians and $10.6+3.4$ for surgeons. Consistent with our finding, a study ${ }^{8}$ conducted in a university hospital demonstrated inadequate performance of physicians on duty in simulated cardiac arrests, regardless of specialty, whether clinical or surgical. Only $1 / 3$ of the physicians performed intubation in less than 35 seconds and only $31 \%$ and $40 \%$ of them, respectively, were able to adequately manage a simulated CA with ventricular fibrillation and asystole.

Study limitations - A non-probability sample was used in this study. It is clear that research conducted with probability samples is superior as regards the generalization of results. Therefore, we recognize the limitations when using convenience sampling. Thus, our results should not be generalized, because of possible biases inherent to the process of sample selection.

Since emergency physicians agreed to participate by signing the written informed consent form, a selection bias may have occurred. However, the professionals who refused to participate may have been those who felt less comfortable with answering about the theme, which would have made the mean score even lower, thus not leading to a significant difference in relation to the results observed in this study. Another fact that makes this bias unlikely is that we were able to obtain a sample with more than $80 \%$ of the emergency physicians in most of the hospitals.

Our study failed in not considering that many professionals who work in public hospitals also work in private hospitals (this datum was not collected). However, each physician filled out the questionnaire only once, that is, if he/she had already filled out the questionnaire in any hospital, whether public or private, he/she would not fill it out again.

\section{Conclusions}

Based on this study, we can conclude that theoretical knowledge on the care of CA patients was higher among professionals who had attended the ACLS course, as opposed to those who had attended the ATLS course. Specialists in Cardiology who had attended the ACLS course demonstrated a higher theoretical knowledge on the care of CA patients when compared to other specialties taken together - Internal Medicine, Surgery and Orthopedics. In the subgroup analysis of all cardiologists, we identified that those who had attended the ACLS presented a higher level of knowledge on resuscitation in comparison to those who had not attended the course. 
Filgueiras Filho et a

ASSESSMENT OF THE GENERAL KNOWLEDGE OF EMERGENCY PHYSICIANS FROM

HOSPITALS OF THE CITY OF SALVADOR (BRAZIL) ON THE CARE OF CARDIAC ARREST PATIENTS

Original Article

\section{References}

1. Cummins RO, Ornato JP, Thies WH, et al. Improving survival from sudden cardiac arrest: The chain of survival concept. AHA Medical/Scientific statement. Circulation. 1991; 83: 1832-47.

2. Van Olden GD, Meeuwis JD, Bolhuis HW, et al. Clinical impact of advanced trauma life support. Am J Emerg Med. 2004; 22(7): 522-5.

3. Timerman SS, Quilici AP, Paiva E, et al. Cursos de Suporte cardíaco básico e avançado de vida: experiência em centro de treinamento no Brasil. Arq Bras Cardiol Supl. Set, 2001.

4. Shannon FL, Jurkovich GJ, Hansbrough JF. Assessment of the proficiency of the surgeon in providing basic and advanced cardiac life support. Surg Gynecol Obstet. 1984;159: 9-12.

5. Lowestein SR, Sabyan EM, Lassen CF, et al. Benefits of training physicians in advanced cardiac life support. Chest. 1986; 89: 512-6.

6. Dane FC, Russell-Lindgren KS, Parish DC, et al. In-hospital resuscitation association between ACLS training and survival to discharge. Resuscitation. 2000; 47: 83-7.

7. Moretti MA. Eficácia do treinamento em suporte avançado de vida nos resultados das manobras de ressuscitação cardiopulmonar. São Paulo, 2001. 130p. Tese (Doutorado) - Faculdade de Medicina, Universidade de São Paulo.

8. Lowenstein S, Libby L, Mountain R, et al. Cardiopulmonary resuscitation by medical and surgical house officers. Lancet. 1981; 2: 679-81.
9. Mancini ME, Kaye W. A comparison of the results of Mega Code testing with ACLS performance during actual resuscitations - a pilot study. Crit Care Med. 1987;15: 368.

10. Stiell IG, Wells GA, Field B, et al. Advanced Cardiac Life Support in out-ofhospital cardiac arrest. N Engl J Med. 2004; 351(7): 647-56.

11. Galinski M, Loubardi N, Duchossoy MC, et al. In-hospital cardiac arrest resuscitation: medical and paramedical theory skill assessment in an university hospital. Ann Fr Anesth Reanim. 2003; 22(3):179-82.

12. Diaz AA, Berria TS, Hermida DC, et al. Conocimientos teóricos de los Médicos de Familia sobre reanimatión cardiopulmonar. Rev Cuba Med Gen Integr. 2002; 18(2): 5-11.

13. Toapanta EP, Troya ME, Córdova G, et al. Conocimiento médico sobre reanimatión cardiopulmonar. Rev Med Cient (Quito). 1997; 9: 71-6.

14. Wheatley LL, Pérez ET, Macías AS. Estado actual de la reanimatión cardiopulmonar en Monterrey, Nuevo León, México. Arch Inst Cardiol Méx. 1988; 58(3): 237-41.

15. Birnbaum ML, Kuska BM, Stone HL, et al. Need for advanced cardiac lifesupport training in rural, community hospitals. Crit Care Med. 1994; 22(5): 735-40

16. Canesin MF, Grion CC. Cartas ao Editor. Arq Bras Cardiol. 2001; 77: 196-7.

17. Devlin M. An evaluative study of the basic life support skills of nurses in an independent hospital. J Clin Nurs. 1999; 8(2): 201-5. 